\title{
Early results of Ceramic on Ceramic versus Ceramic on highly cross linked polyethylene Total Hip Arthroplasty
}

\author{
Ahmed Mohamed Khairy, Adnan Abd El-Aleem El Sebaie, and Mohamed Abd El Monem Negm \\ Department of Orthopedic Surgery, Faculty of Medicine, Al-Azhar University \\ Corresponding author: Ahmed Mohamed Khairy, email: ahmedkhairyortho@gmail.com, mobile: 00201119906630
}

\begin{abstract}
Background: Nowadays, other bearing surfaces such as ceramic on highly cross-linked polyethylene (HXLPE) and ceramic on ceramic have been proposed as an alternative to metal on polyethylene as a solution to osteolysis and loosening. Purpose: it was to spot light on a comparison of early results of use two different bearing surfaces, ceramic on ceramic versus ceramic on HXLPE in primary total hip replacement

Materials and Methods: this is a prospective comparative study which was conducted during the period from June 2016 to April 2019 with mean follow up two years. It included 38 patients (42 hips) which were undergone for total hip replacement (THR) due to end stage arthritis. Of these, there were 22 ceramic on ceramic and 20 ceramic on HXLPE implants. These cases were operated upon Al-Azhar University Hospitals (Al-Hussein \& Bab El-Shaeria). Results: No statistically significant difference in clinical and radiological outcomes scores between the two studied groups with higher rate of implant related fracture and squeaking in ceramic on ceramic group.

Conclusions: there was no statistically significant difference in the clinical and radiological outcome between the two studied groups at the time of last clinical follow-up. Long-term follow-up is required for further evaluation.
\end{abstract}

Keywords: ceramic on ceramic, total hip replacement, HXLPE.

\section{INTRODUCTION}

The aim of new hip-bearing materials is to extend implant life by markedly decreasing the amount of wear debris generated, thus considerably reducing or even eliminating the incidence of osteolysis and loosening ${ }^{(1)}$.

The polyethylene wear is directly linked to rate of osteolysis. In an attempt to decrease wear rates, various combinations of materials in THA such as ceramic-on-ceramic, metal-on-metal, and ceramic-onmetal have been employed, with the most recent being HXLPE $^{(2)}$.

Replacing the polyethylene liner with ceramic seems to be an ideal option, especially in young, active patients. They have the mechanical advantages of wear debris reduction and reduction of subsequent debrisinduced osteolysis. In contrast to lower wear rate, concerns exist regarding the cost and adverse events, such as ceramic fractures and audible squeaking ${ }^{(3)}$.

Newer bearing surfaces in current clinical practice (Ceramic on ceramic, ceramic on HXLPE) showed promise in decreasing the wear rates ${ }^{(4)}$.

Some randomized, controlled trials (RCTs) have been conducted comparing ceramic on ceramic (COC) and C/HXLPE THAs to determine the optimal bearing surface, but different studies reached different conclusions ${ }^{(4)}$.

\section{MATERIALS AND METHODS}

This is a prospective comparative study which was conducted during the period from June 2016 to April 2019 with mean follow up two years. It included 38 patients with 42 hips who underwent primary total hip replacement (THA) due to end stage arthritis, of these, there were 22 ceramic on ceramic and 20 ceramic on
HXLPE implants. The patients were operated upon AlAzhar University Hospital. The mean age of ceramic on ceramic group was 39.74 while the mean age in ceramic on HXLPE group was 44.1.Demographic data of patients are shown in table (1).

In all cases, cementless, both femoral and acetabular, components were used. The patients were evaluated preoperatively. Evaluation included an assessment of complete history, physical examination, and scoring of the patients' condition according to the Harris Hip Score (HHS), laboratory evaluation, and a complete radiological evaluation.

The procedure was performed under spinal anesthesia in all cases. The direct lateral approach was utilized in all patients. Regular follow-up visits were made and re-evaluation was carried out at 6 weeks, 3 , 6, and 12 months and then yearly.

The HHS is a comprehensive, widely accepted scoring system that is used for the clinical evaluation of patients, preoperatively and postoperatively at 6 weeks, 6 and 12 months, and yearly thereafter until the last follow-up. The score is considered excellent if it is between 90 and 100, good between 80 and 90, and fair between 70 and 80 , whereas scores below 70 are considered poor. Standard radiographs were obtained for all patients immediately postoperatively and at subsequent follow up assessments. Acetabular component inclination and position of screws. Acetabular inclination was determined in relation to the interteardrop line.

Femoral stem alignment if the tip of the stem is central, it is in neutral alignment. If the tip is pointed or resting on the lateral cortex, it is in varus 
alignment. If the tip is pointed or resting on the medial cortex, it is in valgus alignment.

\section{Ethical statement:}

The patients received an explanation about the nature, purpose and potential risks of the study. An informed written consent was taken prior to surgery. The study was approved by the Ethics Board of AlAzhar University.

\section{Statistical analysis}

Data were analyzed using Statistical Program for Social Science (SPSS) version 15.0.
Quantitative data were expressed as mean Istandard deviation (SD). Qualitative data were expressed as frequency and percentage.

The following tests were done:

Independent-samples t-test of significance: was used when comparing between two means.

Chi-square test: was used when comparing between non-parametric data.

Probability (P-value)

- P-value $<0.05$ was considered significant.

- $\quad$ P-value $<0.001$ was considered as highly significant.

- P-value $>0.05$ was considered insignificant.

Table (1): Patient demographic data

\begin{tabular}{|c|c|c|c|c|}
\hline \multicolumn{2}{|l|}{ Variables } & $\begin{array}{l}\text { Ceramic } \\
(N=19)\end{array}$ & $\begin{array}{l}\text { HXLPE } \\
(\mathbf{N}=19)\end{array}$ & P-value \\
\hline \multirow{2}{*}{$\begin{array}{l}\text { Follow up period } \\
\text { (months) }\end{array}$} & Mean & 23.8 & 22.8 & \multirow{2}{*}{$>0.05$} \\
\hline & \pm SD & 5.3 & 5.9 & \\
\hline \multirow{2}{*}{ Gender } & Male & 10 & 9 & \multirow{2}{*}{$>0.05$} \\
\hline & Female & 9 & 10 & \\
\hline \multirow{2}{*}{$\begin{array}{l}\text { Age } \\
\text { (years) }\end{array}$} & Mean & 39.74 & 44.1 & \multirow{2}{*}{$>0.05$} \\
\hline & \pm SD & 6.23 & 7.5 & \\
\hline \multirow{3}{*}{ Diagnosis } & AVN & $9(40.9 \%)$ & $6(30 \%)$ & \multirow{3}{*}{$>0.05$} \\
\hline & O.A & $11(50 \%)$ & $12(60 \%)$ & \\
\hline & Dysplasia & $2(9.1 \%)$ & $2(10 \%)$ & \\
\hline \multirow{3}{*}{ Side } & Rt. & $10(52.6 \%)$ & $11(57.9 \%)$ & \multirow{3}{*}{0.9} \\
\hline & Lt. & $1.6 \%)$ & $7(36.8 \%)$ & \\
\hline & Bilateral & $5.8 \%)$ & $1(5.3 \%)$ & \\
\hline
\end{tabular}

\section{RESULTS}

The clinical results in this study were evaluated according to the HHS. Evaluation of radiological results included assessment of both the femoral and the acetabular components.

\section{1-Clinical results:}

At the last follow up the mean HHS range were 85.91 in ceramic on ceramic group while it was 85.4 in ceramic on HXLPE group with no statistically significant difference in the scores between the ceramic on ceramic and ceramic on HXLPE groups was observed at any time intervals shown in table (2).

Table (2): HHS results of both studied groups

\begin{tabular}{|c|c|c|c|c|}
\hline \multicolumn{2}{|l|}{$\begin{array}{l}\text { H.H.S } \\
\text { Variables }\end{array}$} & $\begin{array}{l}\text { Ceramic } \\
(\mathbf{N}=22)\end{array}$ & $\begin{array}{l}\text { HXLPE } \\
(\mathbf{N}=\mathbf{2 0})\end{array}$ & P-value \\
\hline \multirow{2}{*}{ Pre op score } & Mean & 41.77 & 39.55 & \multirow{2}{*}{$>0.05$} \\
\hline & \pm SD & 6.46 & 5.28 & \\
\hline \multirow[t]{2}{*}{ Post 6-8 weeks } & Mean & 62.55 & 62.60 & \multirow{2}{*}{$>0.05$} \\
\hline & \pm SD & 5.85 & 4.56 & \\
\hline \multirow[t]{2}{*}{ Post 3 month } & Mean & 73.00 & 73.95 & \multirow{2}{*}{$>0.05$} \\
\hline & \pm SD & 5.09 & 3.90 & \\
\hline \multirow{2}{*}{ Post 6 months } & Mean & 82.23 & 82.05 & \multirow{2}{*}{$>0.05$} \\
\hline & \pm SD & 4.61 & 4.95 & \\
\hline \multirow{2}{*}{ Post one year } & Mean & 85.18 & 84.75 & \multirow{2}{*}{$>0.05$} \\
\hline & \pm SD & 5.12 & 5.16 & \\
\hline \multirow{2}{*}{ Last visit } & Mean & 85.91 & 85.40 & \multirow{2}{*}{$>0.05$} \\
\hline & \pm SD & 5.28 & 5.27 & \\
\hline
\end{tabular}




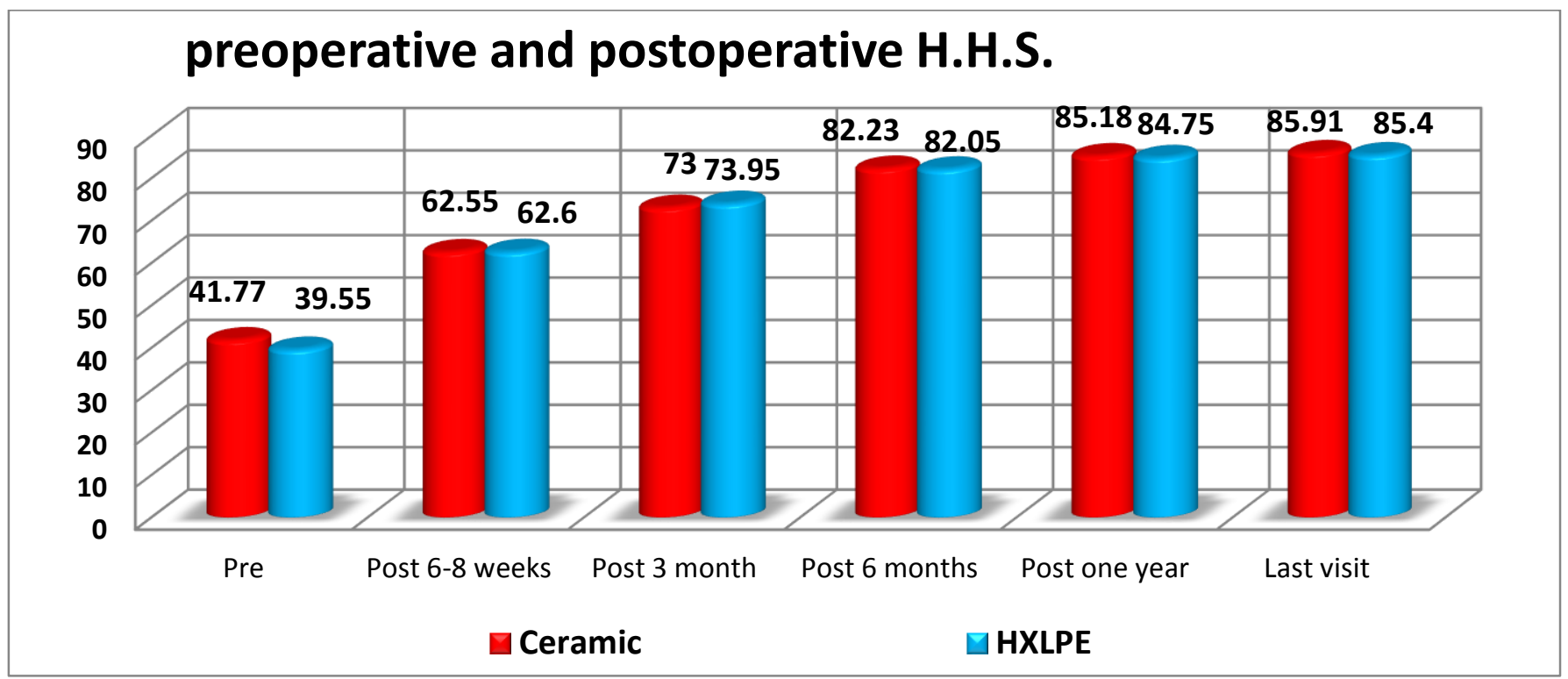

Figure (1): HHS results of both studied groups

\section{2-Patient satisfaction}

As regard HHS, we have 5 excellent, 13 good and 4 fair results were obtained in ceramic on ceramic group while 4 excellent, 12 good and 4 fair results were obtained in ceramic on HXLPE group (table 2).

Table (2): comparison between studied groups as regard patient satisfaction.

\begin{tabular}{|c|l|l|l|l|}
\hline \multicolumn{1}{|c|}{ Variables } & $\begin{array}{l}\text { Ceramic } \\
\text { (N=22 hip) }\end{array}$ & $\begin{array}{l}\text { HXLPE } \\
(\mathbf{N}=\mathbf{2 0} \text { hip) }\end{array}$ & P-value \\
\hline \multirow{3}{*}{ Satisfaction } & Excellent & $5(22.7 \%)$ & $4(20 \%)$ & \multirow{2}{*}{$>0.05$} \\
\cline { 2 - 5 } & Good & $13(59.1 \%)$ & $12(60 \%)$ & $>$ \\
\cline { 2 - 5 } & Fair & $4(18.2 \%)$ & $4(20 \%)$ & \\
\hline
\end{tabular}

This table shows no statistical significant difference (p-value $>\mathbf{0 . 0 5}$ ) between studied groups as regard patient satisfaction.

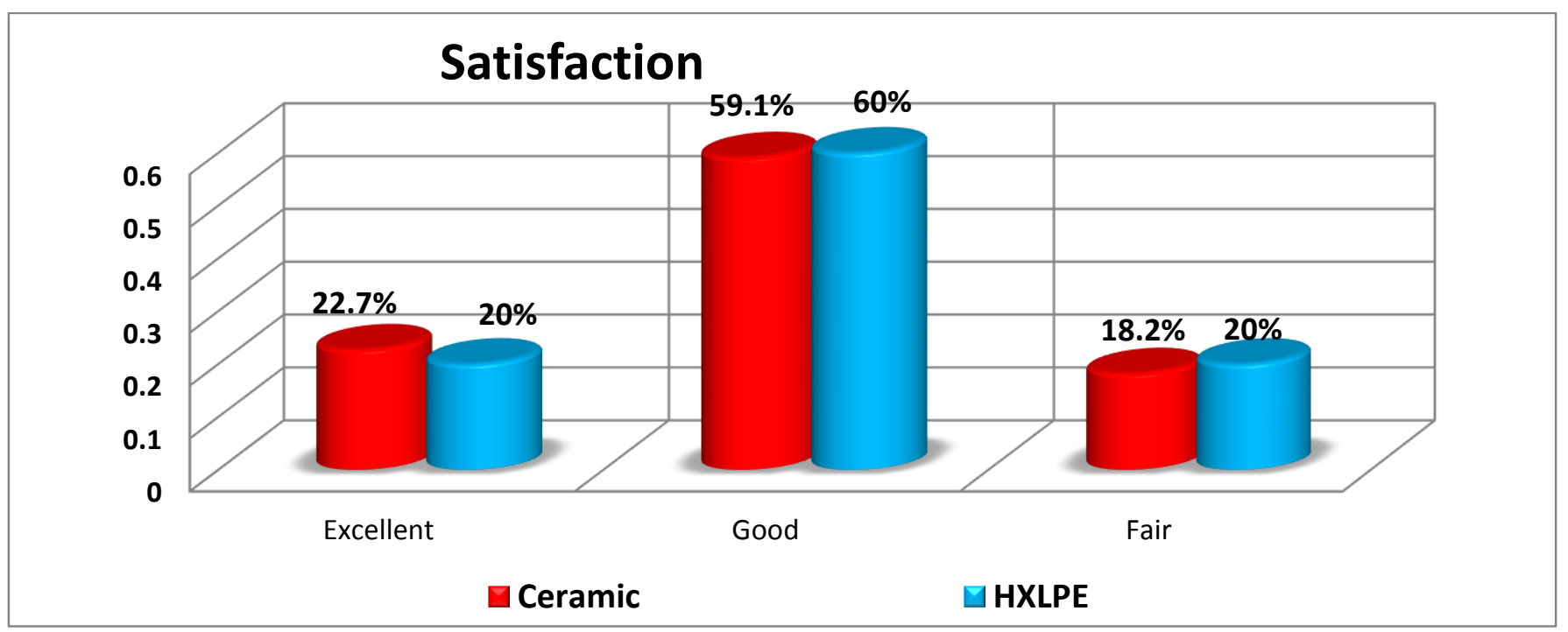

Figure (2): comparison between studied groups as regard patient satisfaction. 


\section{3-Radiological results}

The mean cup inclination in ceramic on ceramic (COC) group was 52.27 while in ceramic on HXLPE group was 47.5.

All stems were in a neutral position, except four stems in ceramic on ceramic (COC) group and 3 in $\mathrm{C} / \mathrm{HXLPE}$ group were in slight valgus.

\section{4-Radiological follow-up}

(1) There were no progressive radiolucent areas behind any cup in the last follow-up.

(2) There were no reported cases of early osteolysis.

(3) There were no reported cases with heterotopic ossification.
(4) There were no reported cases with a change in the stem position or migration.

(5) There were no reported cases with cup rotation or migration.

(6) There were no reported cases with broken heads.

In one case in which there was an intraoperative crack around the acetabular component tin COC group, there was complete union of the crack with no change in the position of the cup.

Table (3) shows no statistical significant difference (p-value $>\mathbf{0 . 0 5}$ ) between studied groups as regard radiological data.

Table (3): radiological results

\begin{tabular}{|c|c|c|c|c|}
\hline \multicolumn{2}{|l|}{ Variables } & Ceramic $(N=22)$ & HXLPE $(N=20)$ & P-value \\
\hline \multirow{2}{*}{$\begin{array}{l}\text { Femoral stem } \\
\text { position }\end{array}$} & Neutral & 18 & 17 & \multirow[t]{2}{*}{$>0.05$} \\
\hline & valgus & 4 & 3 & \\
\hline \multicolumn{2}{|c|}{$\begin{array}{l}\text { Radiolucent lines(zones) } \\
\text { and osteolysis }\end{array}$} & $\begin{array}{l}\text { Stress shielding in } \\
\text { most cases } \\
\text { No other RLL }\end{array}$ & $\begin{array}{l}\text { Stress shielding in } \\
\text { most cases } \\
\text { No other RLL }\end{array}$ & $-\cdots$ \\
\hline \multicolumn{2}{|l|}{ Instability } & No & No & $>0.05$ \\
\hline \multicolumn{2}{|l|}{ Subsidence } & No & No & $>0.05$ \\
\hline \multicolumn{2}{|l|}{ Pedestal } & No & No & $>0.05$ \\
\hline \multirow[t]{2}{*}{ Inclination } & Mean & 52.27 & 47.5 & \multirow[t]{2}{*}{$>0.05$} \\
\hline & $\pm \mathrm{SD}$ & 58.71 & 41.28 & \\
\hline \multirow[t]{2}{*}{ Radiolucent lines } & zone 1 & & 1 & \\
\hline & zone 2 & 2 & 2 & \\
\hline \multicolumn{2}{|l|}{ Migration } & No & No & $>0.05$ \\
\hline
\end{tabular}

\section{Complications:}

In studied groups we have one patient with intraoperative ceramic chipping, one patient with squeaking and two cases of reversible sciatic nerve palsy.

No reported cases were reported of revision, dislocation, deep infection, deep venous thrombosis and pulmonary embolism (table 4).

Table (4): comparison between studied groups as regard postoperative complications

\begin{tabular}{|l|c|c|c|}
\hline Variables & Ceramic $\mathbf{N}=\mathbf{2 2})$ & HXLPE $(\mathbf{N}=\mathbf{2 0})$ & P-value \\
\hline Revision: Cup Stem Liner or head & $0(0 \%)$ & $0(0 \%)$ & $>0.05$ \\
\hline Ceramic fracture & $0(0 \%)$ & $0(0 \%)$ & $>0.05$ \\
\hline Dislocation & $0(0 \%)$ & $0(0 \%)$ & $>0.05$ \\
\hline Ceramic liner chip & $1(4.5 \%)$ & $0(0 \%)$ & $>0.05$ \\
\hline Intraoperative fracture & $1(4.5 \%)$ & $1(0 \%)$ & $>0.05$ \\
\hline Deep joint infection & $0(0 \%)$ & $0(0 \%)$ & $>0.05$ \\
\hline Superficial wound infection & $0(0 \%)$ & $1(5 \%)$ & $>0.05$ \\
\hline Deep venous thrombosis & $0(0 \%)$ & $0(0 \%)$ & $>0.05$ \\
\hline Pulmonary embolism & $0(0 \%)$ & $0(0 \%)$ & $>0.05$ \\
\hline Heterotopic bone ossification & $0(0 \%)$ & $0(0 \%)$ & $>0.05$ \\
\hline Squeaking & $1(4.5 \%)$ & $0(0 \%)$ & $>0.05$ \\
\hline Sciatic nerve palsy & $2(9.1 \%)$ & $0(0 \%)$ & $>0.05$ \\
\hline
\end{tabular}




\section{DISCUSSION}

Different theory is ongoing regarding the optimal bearing surfaces for THA, especially in young patients as young patients are expected to place higher demands on THAs because they are more active and have a longer life expectancy ${ }^{(5)}$

Because of lower wear and osteolysis rates, ceramic bearing surfaces are increasingly used for THA, especially in young, active patients .Ceramic could be used as a hard-on-soft articulation with a polyethylene liner or as a hard-on-hard articulation with a ceramic liner. ${ }^{(6)}$

In our study the results showed that except for a higher squeaking rate for COC THA, there were similar results in the rates of revision, osteolysis and radiolucent lines, loosening, dislocations, intra- and postoperative implant fractures, deep infection, deep venous thrombosis, and pulmonary embolus between the COC and COP THA groups.

A major long-term complication of THA is aseptic loosening, which accounts for more than half of all revisions. Although the etiology of aseptic loosening is not clear, there is a general acceptance that aseptic osteolysis and subsequent implant failure occur because of a chronic inflammatory response to implant-derived wear particles ${ }^{(7)}$.

A postoperative radiographic analysis demonstrated that the mean linear wear rate in a COC THA was statistically lower than that in a COP THA (8) .

Lombardi et al. ${ }^{(9)}$ reported decreased rates of wear, osteolysis, and aseptic loosening with COC bearing surfaces.

In our study, no significant differences were found regarding the rates of osteolysis, loosening, and revision between the 2 types of bearing surfaces in the short term follow-up.

Squeaking is a recognized complication of THA with COC bearing surfaces, but squeaking is not unique to ceramic bearings. Squeaking was also reported with metal-on-metal THA ${ }^{(10)}$.

The reported incidence of squeaking after COC THA varies between $0.3 \%$ and $20.9 \%$ (11).

The squeaking rate in our study was $4.5 \%$, which is consistent with the reported rate in the literature. There were no cases of squeaking in the COP group. This difference was insignificant.

In our study we reported a case of Chipping of the alumina acetabular liner occurred during and remained in the ring without secondary complications but no statistically significant difference in intra- and postoperative implant fracture rates between the COC and COP groups.

In a prospective study of Kim et al. ${ }^{(13)}$ all of the reported intra- and postoperative implant fractures occurred in the COC group. The total incidence of intra- and postoperative implant fractures in the COC group was higher than that in the COP group.

Ceramic liner fractures typically occur during the process of inserting the ceramic liner into the metal acetabular cup due to improperly seated liners or cup deformation, which could result from tapping the edge of the cup in an attempt to adjust its position, especially when impacting the cup into hard bone. The insertion of a ceramic liner requires great attention and precision $^{(14)}$.

We also reoprted in our study 2 cases of reversible sciatic nerve palsy but it mostly related to surgical technique rather than bearing surfaces.

\section{LIMITATIONS}

1- Limited number of cases.

2- Surgeries was done by more than one surgeon

3-Short period of follow up.

This study can be improved by obtaining a larger number of patients, which would allow for stratification and accurate subgroup analysis as well. In addition, increasing the period of follow-up would enable us to ascertain the survivorship of our implants in the longer term. Another advantage of longer follow-up would be to assess the durability of this ceramic endoprosthetic system as it will only be confirmed after a follow-up of over 15 years.

\section{CONCLUSION}

In summary, both ceramic on ceramic $(\mathrm{CoC})$ and ceramic on HXLPE bearings can obtain a good and similar functional outcomes following primary THA. The ceramic on ceramic bearing appears to have a lower liner wear rate, but a statistically higher incidence of component-related noise and ceramic component fracture than ceramic on HXLPE bearing. There is no clear evidence favoring the use of either a ceramic on ceramic or ceramic on HXLPE bearing surfaces in primary THA, further studies with highquality and longer term follow-up to provide more evidence on this topic are still required.

\section{REFERENCES}

1. HarrisW (2001): Wear and periprosthetic osteolysis: the problem. Clin Orthop Relat Res., 393:66-70.

2. Bozic KJ, Kurtz SM (2009): The epidemiology of revision THA in the United States. J Bone Joint Surg.,91A:128.

3.Bizot P, Banallec L, Sedel L, Nizard $R$ (2000): Alumina-on-alumina total hip prostheses in patients 40 years of age or younger. Clin Orthop Relat Res., 379:68-76. 4. Shetty V, Shitole B, Shetty G, Thakur H, Bhandari M (2011): Superior bearing surfaces for THR in the young active patient: A meta-analysis. Int Orthop., 35:1281-7. 
5. D'Antonio JA, Sutton K (2009): Ceramic materials as bearing surfaces for total hip arthroplasty. J Am Acad Orthop Surg., 17(2):63-68.

6.Traina F, De Fine M, Di Martino A, Faldini C (2013): Fracture of ceramic bearing surfaces following total hip replacement: a sys ᄀtematic review. https://www.ncbi.nlm.nih.gov/pubmed/23844356

7. Holt G, Murnaghan C, Reilly J, Meek RM (2007): The biology of aseptic osteolysis. Clin Or $\neg$ thop Relat Res.,460:240-252.

8.Amanatullah DF, Landa J, Strauss EJ, Garino JP, Kim SH, Di Cesare PE (2011): Comparison of surgical outcomes and implant wear between ceramic-ceramic and ceramic on HXLPE articulations in total hip arthroplasty. J Arᄀthroplasty, 26(6):72-77.

9.Lombardi AV Jr, Berend KR, Seng BE, Clarke IC, Adams JB (2010): ceramic-on- ceramic articulation in primary THA: prospective, randomized FDA-IDE study and retrieval analysis. Clin Orthop Relat Res., 468(2):367374.
10. Kiyama T, Kinsey TL, Mahoney OM (2013): Can squeaking with ceramic-on-ceramic hip articulations in total hip arthroplasty be avoided? J Arthroplasty, 28(6):1015- 1020.

11. Keurentjes JC, Kuipers RM, Wever DJ, Schreurs BW (2008): High incidence of squeaking in THAs with alumina on alumina bearings. Clin Orthop Relat Res., 466(6):1438-1443.

12. Restrepo C, Parvizi J, Kurtz SM, Sharkey PF, Hozack WJ, Rothman RH (2008): The noisy ceramic hip: is component malpositioning the cause? J Arthroplasty, 23(5):643-649.

13. Kim YH, Park JW, Kulkarni SS, Kim YH et al. (2013): A randomised prospective evaluation of ceram $\neg$ icon-ceramic and ceramic-on-HXLPE bearings in the same patients with cementless total hip arthroplasty. Int Orthop., 37(11):2131- 2137.

14.Hamilton WG, McAuley JP, Dennis DA, Murphy JA, Blumenfeld TJ, Politi J (2010): THA with Delta ceramic on ceramic: results of a multicenter investigational device exemp $\neg$ tion trial. Clin Orthop Relat Res., 468(2):358-366. 